Peer-Reviewed Article

ISSN: 2162-3104 Print/ ISSN: 2166-3750 Online

Volume 6, Issue 2 (2016), pp. 542-565

(C) Journal of International Students

http://jistudents.org/

\title{
Assessing Domestic vs. International Student Perceptions and Attitudes of Plagiarism
}

\author{
Daniel Adrian Doss \\ University of West Alabama (USA) \\ Russ Henley \\ University of West Alabama (USA) \\ Balakrishna Gokaraju \\ University of West Alabama (USA) \\ David McElreath \\ University of Mississippi (USA) \\ Hilliard Lackey \\ Jackson State University (USA) \\ Qiuqi Hong \\ University of West Alabama (USA) \\ Lauren Miller \\ University of West Alabama (USA)
}

\section{ABSTRACT}

The authors examined students' perceptions of plagiarism from a higher education teaching institution within the U.S. southeast. This study employed a five-point Likert-scale to examine differences of perceptions between domestic versus international students. 
Statistically significant outcomes were observed regarding the notions that plagiarism is a necessary evil and that plagiarism is illegal. Respectively, the analyses of the means showed that respondents tended toward disagreement concerning the former notion and neutrality regarding the latter notion.

Keywords: domestic students; international students; education; higher education; plagiarism

Plagiarism affects academic and professional settings globally regardless of size, scope, or mission. Despite the best efforts of individuals and organizations to dissuade plagiarism, no guarantee exists that any setting will be unaffected by plagiaristic incidents. Observed from the discussions of Qi (2015), Doss et al. (2015c), Towell, et. al. (2012), Mundava and Chaudhuri (2007), and Maurer, Kappe, and Zaka (2006), plagiarism affects a variety of agents: 1) plagiarists; 2) those from whom materials were acquired; 3) and any stakeholders who may have vested interest regarding the incident of plagiarism.

Given the unchanging attributes of human nature that transcend nationalities and cultures, both domestic and international students may be tempted to plagiarize. During the 2014 academic year, it was estimated that approximately 8,000 Chinese students were expelled from American universities for reasons involving cheating and unsatisfactory performance academically (Qi, 2015). Some research studies suggested that international students are at least "twice as likely as domestic students" to exhibit a lack of understanding regarding methods of avoiding academic breaches of integrity (Bretag, 2013, p.1).

Plagiarism is exhibited in a variety of fashions, both tangibly (e.g., in writings, videos, etc.) and intangibly (e.g., in concepts, ideas, etc.). Although plagiarism is a reality of academic settings, little consensus exists regarding the types of punishments and sanctions that may be levied against plagiarists (Doss, et al., 2015c). Certainly, motivations for committing acts of plagiarism may range from a lack of familiarity with language by international students to merely not knowing how to convey concepts and ideas. Other factors, such as the pressures of timed examinations and unfamiliarity with American academic 
protocols, also contribute toward acts of academic misconduct among international students (Bista, 2011). Regardless of modality or motivation, individuals who have an awareness of plagiarism may form opinions, perceptions, and judgments of such incidents. Given these notions, this research endeavor examines various perceptions of plagiarism that exist between domestic versus international students.

The host institution for this study was a Southern, regional Division-II university whose mission emphasized teaching instead of research. Geographically, the host institution represented a rural entity, and its corresponding town exhibited approximately 1,800 residents. Its overall student enrollment numbered approximately 5,000 students, both physically and virtually. Its physical campus exhibited an enrollment of nearly 2,500 students whereas the remainder were enrolled among online programs. This study was performed within the College of Business at the University of West Alabama which enrolled a total of 312 students. Within the College of Business, the degrees offered by the host institution were the Master of Business Administration (MBA) and Bachelor of Business Administration (BBA). Within the BBA program, degree concentrations included accounting, finance, information systems, management, marketing, and technology. The MBA consisted of general and finance concentrations. A total of 267 students were enrolled in the BBA program whereas 45 were MBA students. A ratio of 1 faculty to 15 students permeated the academic setting.

\section{LITERATURE REVIEW}

Among academic settings, a typical definition of plagiarism is akin to the following:

Failure to properly document all materials from sources, published or otherwise, that are included in an essay, research paper, examination, or other assignment. This includes items such as definitions of particular terms taken from a research source. Incidents of plagiarism include quoting or paraphrasing without properly crediting the author, using the syntax of a source document in a paraphrase 
without significant modifications, or incorporating the ideas of another without attribution by standard documentation. (University of West Alabama, 2015)

It is not uncommon for academic institutions to experience problematic situations involving plagiarism. Generally, instances of plagiarism have often been perceived as the transgressing of Western customs among academic settings (Currie, 1998). Such instances of plagiarism have been deemed intentional actions committed purposefully (Currie, 1998), and some have likened such events to acts of intellectual thievery (Maurer, Kappe, \& Zaka, 2006). Others have deemed acts of plagiarism to be victimless crimes (Shah, 2012).

Some institutions may necessitate the failing or expulsion of offenders from the academic setting; some may invoke suspensions, some may necessitate "training exercises" as punitive measures while others may issue various forms of reprimand, or merely a warning (Maurer, Kappe, \& Zaka, 2006, p. 1053). More punishments also include the rescission of degrees or certificates, and the referring of incidents to the external criminal justice system (Maurer, Kappe, \& Zaka, 2006). Thus, no standard method exists for addressing instances of plagiarism universally.

During recent years, a most embarrassing example of the dangers and consequences of plagiarism involved the resignation of Germany's defense secretary following the discovery that he had plagiarized much of his graduate thesis. According to Lose (2011), approximately $20 \%$ of his thesis involved plagiarism, and 270 of its 393 pages were copied from other sources. As a result, his degree was rescinded (Lose, 2011). Given these observations, the temptations of plagiarism affect even the highest of government officials.

Even academic administrators are susceptible to the temptations of plagiarism. The dean of the medical school at the University of Alberta resigned after allegations were made that portions of one of his speeches were plagiarized (Dyer, 2011). In this instance, the allegations of plagiarism were levied by students (Dyer, 2011). Given the responsibilities of a deanship, regarding plagiarism, this example alludes to an instance of hypocrisy among academic leaders.

A contemplation of the preceding excerpts from the literature (University of West Alabama, 2015; Shah, 2012; Dyer, 2011; Lose, 
2011; Maurer, Kappe, \& Zaka, 2006; Currie, 1998) provides various themes:

1) Plagiarism may be perceived as an intentional form of criminality because it involves taking another's materials without permission or attribution, and using them as though they were the offender's original entities;

2) No universal, punitive paradigm exists regarding the punishing of offenders. Each institution approaches plagiarism uniquely. Punitive measures range vastly from simple warnings and reprimands to the rescinding of degrees and the referring of incidents to the criminal justice system.

3) Plagiarism is not illegal despite being unethical.

4) Plagiarism occurs among environments that are external to academia.

5) Plagiarism occurs within academia.

6) Plagiarism affects all levels of society.

7) Plagiarism affects both domestic and international students.

Essentially, these four themes may be summed up with a single statement: plagiarism is ubiquitous. Any organization or environment is susceptible to the wiles of plagiarism. Certainly, many examples are prominent among academic settings ranging from student dismissals to the revoking of titles and qualifications. Outside of academia, such events have occupied time among courtrooms within the justice system. Legal remedies are often pursued regarding allegations of plagiarism. For instance, familiar plagiarism court cases involved disputes ranging from the lyrics for Vanilla Ice's song Ice Ice Baby to Alone Again by Biz Markie (Demers, 2006). Such disputes involve a plethora of copyright issues that must be addressed within the court system (Doss, Glover, Goza, \& Wigginton, 2015). However, because copyright laws differ among nations and cyber-law is a relatively new specialty, some amount of ambiguity exists regarding the legalities of international issues (McElreath et al., 2013). Although these instances are examples of copyright law violations, no law exists against plagiarism itself (Posner, 2007).

Instances of plagiarism transcend academic disciplines and languages. Zhang et al. (2013) examined surveys regarding the plagiarizing of computer program source code among university 
students. Similarly, Cowling (2012) explored instances of plagiarism within the discipline of mathematics and Yang (2014) indicates that plagiarism occurs in the discipline of chemistry.

Motivations for plagiarism are diverse. Among international students, ineptness and unfamiliarity with language may be influential factors (Wilkinson, 2009). For instance, a research study sponsored by the University of Minnesota showed that approximately $85 \%$ of plagiarism instances were associated with students whose native tongues were not English (Mundava \& Chaudhuri, 2007). External to American society, some cultures do not find it offensive to use exact words, concepts, or ideas that originated elsewhere. Some cultures consider such works to be owned by the "whole society," and not by individuals (Mundava \& Chaudhuri, 2007, p. 171). Because of this perception, attribution of sources is deemed unnecessary among such societies (Mundava \& Chaudhuri, 2007, p. 171). Cultural differences therefore have the potential of affecting instances of plagiarism that occur among American institutions involving international students.

The current student body of the host institution population represents a diverse array of future professionals that who must be mindful of plagiarism during their careers. After graduation, regardless of national origin, many alumnae enter professional careers whereby they must adhere to the highest ethical standards within their respective professions. Conformance to ethical standards and exhibiting strong professionalism is expected among all professions.

Business graduates have the potential of becoming social scientists depending upon their choice of careers. In such cases, depending upon the type of career pursued, codes of ethics may govern the actions of both international and domestic alumnae. Codes of ethics exist among professional social science and business organizations, such as the American Psychological Association and the American Marketing Association. The tenets of such codes of ethics decry the very nature of plagiarism. Students often study a code of ethics in their coursework. Among American institutions, student ethical codes exist for a variety of majors, and business curriculums often incorporate courses in business ethics. Given the advent and proliferation of globalization and its effects academically, some question whether reconciliation should occur regarding differences 
that exist "between the perceptions and laws at home" versus those of "foreign countries" (Towell, et. al., 2012, p. 96).

During recent years, the host institution experienced a variety of plagiarism incidents involving both domestic and international students whose actions involved copying entire papers or sections of papers from Internet sources without attribution. Similarly, during the same period, the host institution entered a variety of international agreements with foreign institutions through which it increased its overall enrollment by including numerous international students within its College of Business. Given that a greater diversity of nationalities - representing both global hemispheres - exists within the student populace than was exhibited five years ago, numerous opinions and perceptions exist among students regarding the notion of plagiarism. An initial survey of these business students, stratified by graduate versus undergraduate students, showed that plagiarism was not perceived as a necessary evil (Doss et. al, 2015a). The study also showed that few perceptions existed regarding plagiarism as being unprofessional and that few perceptions existed regarding plagiarism as being illegal (Doss et. al, 2015a).

This study examines differences between American domestic students versus international students regarding: a) whether plagiarism is deemed a necessary evil given ineptness of language among international students, b) whether plagiarism is deemed as unprofessional given ethical differences among countries, and c) whether plagiarism is deemed illegal given legal differences among nations. This research question was divided into three sub-questions, as follows:

1. Do respondents perceive plagiarism as a necessary evil?

2. Do respondents perceive plagiarism as unprofessional?

3. Do respondents perceive plagiarism as illegal?

\section{RESEARCH METHOD}

The research setting represented physical classroom environments exhibiting domestic and international students. This study was approved by the local Institutional Review Board because it involved the use of human subjects. Students were notified of the principles of informed consent. Students were free to opt out of the study at any 
time. This study examined two types of students: domestic and international. For the purposes of this study, domestic students were defined as those students whose country of origin was the United States of America whereas international students were defined as students whose countries of origin were elsewhere.

A sample size of 178 respondents was generated. This study used a Likert-scale instrument to collect data about student perceptions of plagiarism within the College of Business. Within the Likert-scale, the value of 1 represented "strongly disagree," the value of 3 represented "neutral," and the value of 5 represented "strongly agree." Tables 1 through 3 show survey items and their corresponding statements. Survey questions were derived by considering attributes of plagiarism that occurred at the host institution, consulting with professorial colleagues in the disciplines of education and business, and from observations of student behaviors and materials.

Survey questions also were fashioned after the inquiries of Howard, Ehrich, and Walton (2014) regarding specific question topics. They survey was developed by categorizing related questions into specific groups which were the basis of composite scales for numerical analysis. The language of the survey instrument involved specific phrasing to avoid ambiguity and incorporated simplicity among its queries as methods of avoiding any confusion among respondents. Additionally, the survey was designed to require little time for completion thereby diminishing the potential of participative abandonment among respondents.

The survey was disseminated using only the English language. The target population and sample consisted of domestic and international students enrolled in both day and night classes. The host environment exhibited a total of 312 enrollees within its College of Business. Using a confidence level of $95 \%$ and a confidence interval of 5 points, the appropriate sample size was deemed to be a total of 121 respondents. The survey was physically disseminated during the first ten minutes of class meetings for both day and night courses within the College of Business of the host institution thereby ensuring captive audiences. Duplicate respondents were disallowed. Days of survey dissemination were chosen by using the first meeting of a specific course section during the week. 


\begin{tabular}{ll}
\hline Item & Statement \\
\hline 1 & $\begin{array}{l}\text { I can plagiarize if I don't have enough time to meet a } \\
\text { deadline. }\end{array}$ \\
I can't keep from using someone else's materials without \\
citing because there are only so many ways of saying \\
something.
\end{tabular}

Table 2 Section 2 Questions

\begin{tabular}{ll}
\hline Item & Statement \\
\hline 13 & Plagiarism is a temptation because everyone else plagiarizes. \\
14 & Plagiarism quashes intellectual curiosity. \\
15 & Plagiarism within a high-value paper or speech may be ignored. \\
16 & The identities of plagiarists should be announced openly. \\
17 & This academic institution has no plagiarism. \\
\hline & 550
\end{tabular}


18 Plagiarism is not a bad or wrong thing for me to do.

19 I do not feel bad about copying excerpts or whole materials from my previous works, and using them again for another class.

20 In the context of morals and ethics, it is important to discuss plagiarism.

21 People say they do not plagiarize, but do plagiarize materials.

22 Using someone else's materials without proper citing or referencing the other person is not deemed offensive or criminal in my culture.

23 Plagiarism is unacceptable within the context of professionalism

24 I believe plagiarism is unethical

25 I believe plagiarism is immoral

26 I believe plagiarism is criminal

27 I do not report my peers who I know plagiarize.

Table 3 Section 3 Questions

\begin{tabular}{ll}
\hline Item & Statement \\
\hline 28 & $\begin{array}{l}\text { Plagiarists should be punished by law. } \\
\text { Novice researchers or assistants should receive mild } \\
\text { punishment or be merely warned for using some type of } \\
\text { plagiarism. }\end{array}$ \\
30 & $\begin{array}{l}\text { It is justifiable to use my previous works without referencing } \\
\text { myself to complete new works. }\end{array}$ \\
31 & $\begin{array}{l}\text { Plagiarism should be deemed unimportant even though it } \\
\text { involves taking and using another's materials or concepts, but }\end{array}$ \\
not their physical possessions. & $\begin{array}{l}\text { Plagiarism is a form of intellectual theft. } \\
\text { Plagiarizing something is equivalent to stealing an exam or } \\
\text { exam answers. }\end{array}$ \\
Plagiarists should be expelled from professions or \\
occupations and punished appropriately.
\end{tabular}


A total of 178 survey responses were received thereby representing approximately $56 \%$ of the enrollees. This study incorporated a quantitative data analysis. The analytical techniques consisted of analysis of variance (ANOVA), Chi-Squared Method, Cronbach method, and descriptive statistics. The level of significance was 0.05. Stratification involved the use of domestic students versus international students. The Cronbach method was used to explore internal consistency and reliability of the study.

The scaled questions were evaluated through means analyses to determine the characteristics of directionality within the received responses for each of the scales. The constraints and boundaries used within the mean analysis approach are subjective (McNabb, 2010) and were established as follows: 1) if mean $<2.5$, then participant is disagreeing; 2) if $2.5 \leq$ mean $\leq 3.5$, then neither agreeing nor disagreeing; and 3) if mean > 3.5, then agreeing.

The Chi-Squared method was used to determine whether bias influenced the study through examining the distribution of the disseminated survey notices versus the reported distribution that was observed from the returned surveys. The host institution indicated the presence of 222 domestic students and 90 international students enrolled within its College of Business. Using this distribution as a basis for examining the potential of bias, the outcome of the ChiSquare analysis $\left(\alpha=0.05 ; X^{2}=0.000001\right)$ showed a statistically significant outcome, thereby indicating the presence of bias. Additionally, because this research occurred only within a solitary Division-II institution, its outcomes may not be generalizable for other institutions.

The Cronbach method was used to examine the reliability of the research study, and was determined to be 0.84 . Reliability was also examined within each of the separate sections of the survey instrument. The first section exhibited a reliability value of 0.86 ; the second section exhibited a reliability value of 0.67 ; and the third section exhibited a reliability value of 0.74 . According to Tappen (2011), reliability values that exceed 0.70 are deemed acceptable. Although the reliability outcome for the second section was questionable, the remaining and overall reliability values of the study were acceptable. The first survey section queried perceptions regarding whether plagiarism was deemed as a necessary evil, the 
second section queried perceptions regarding whether plagiarism was deemed as unprofessional, and the third section queried perceptions regarding whether plagiarism was deemed as illegal.

\section{RESULTS}

The demographic findings of the study provide insight into the respondent audience. A total of $93.98 \%$ of the respondents were between the ages of 18 and 29 years; $53.85 \%$ of the respondents were male whereas $46.15 \%$ of the respondents were female; and $85.44 \%$ were undergraduates whereas $14.56 \%$ were graduate students. A total of $91.62 \%$ of the respondents were full-time students whereas $8.38 \%$ were part-time students.

\section{Table 4}

Overview of Reported Occupations

\begin{tabular}{lll}
\hline Category & Quantity & Percentage \\
\hline No Response & 3 & $4.55 \%$ \\
Accounting & 10 & $15.15 \%$ \\
Administrative & 6 & $9.09 \%$ \\
Analytical & 3 & $4.55 \%$ \\
Banking & 2 & $3.03 \%$ \\
Customer Service & 2 & $3.03 \%$ \\
Education & 3 & $4.55 \%$ \\
Engineering & 1 & $1.52 \%$ \\
Equestrian & 1 & $1.52 \%$ \\
Financial & 4 & $6.06 \%$ \\
Fitness & 1 & $1.52 \%$ \\
Food Services & 7 & $10.61 \%$ \\
General Labor & 4 & $6.06 \%$ \\
Health Care & 1 & $1.52 \%$ \\
Public Safety & 1 & $1.52 \%$ \\
Management & 6 & $9.09 \%$ \\
Physical Therapy & 1 & $1.52 \%$ \\
Retail & 2 & $3.03 \%$ \\
Sales & 6 & $9.09 \%$ \\
Technical & 2 & $3.03 \%$ \\
\hline
\end{tabular}


Regarding national origin, $69.93 \%$ of the respondents were U.S. citizens (i.e., domestic students) whereas approximately $30.07 \%$ of the respondents indicated a foreign nationality (i.e., international students). A total of $18.07 \%$ of the respondents reported a minimum of at least six years of work experience with a maximum of work experience not exceeding 20 years. Examples of the most popular vocational or professional occupations were accounting, organizational administration, management, and food services.

Numerical descriptions of the first scale, its domestic component, and its international component are presented within Table 5. This scale measured perceptions about the notion that plagiarism is a necessary evil.

\section{Table 5}

Numerical Descriptions for the First Scale (Questions 1 through 12)

\begin{tabular}{lccccc}
\hline Item & Mean & $\begin{array}{c}\text { Standard } \\
\text { Deviation }\end{array}$ & Variance & Mode & Median \\
\hline $\begin{array}{l}\text { Scaled Ques. } \\
1-12\end{array}$ & 1.97 & 1.11 & 1.24 & 1 & 2 \\
Domestic & 1.93 & 1.12 & 1.25 & 1 & 2 \\
International & 2.09 & 1.11 & 1.23 & 1 & 2 \\
\hline
\end{tabular}

\section{Table 6}

Numerical Descriptions for the Second Scale (Questions 13 through 27)

\begin{tabular}{lccccc}
\hline Item & Mean & $\begin{array}{l}\text { Standard } \\
\text { Deviation }\end{array}$ & Variance & Mode & Median \\
\hline Scaled & 2.82 & 1.36 & 1.86 & 1 & 3 \\
Ques. 13-27 & 2.78 & 1.39 & 1.92 & 1 & 3 \\
Domestic & 2.91 & 1.31 & 1.71 & 3 & 3 \\
International & & & & & \\
\hline
\end{tabular}

Numerical descriptions of the second scale, its domestic component, and its international component are presented within Table 6. This 
scale measured perceptions about the notion that plagiarism is unprofessional.

Numerical descriptions of the third scale, its domestic component, and its international component are presented within Table 7. This scale measured perceptions about the notion that plagiarism is illegal.

\section{Table 7}

Numerical Descriptions for the Third Scale (Questions 28 through 35)

\begin{tabular}{lccccc}
\hline Item & Mean & $\begin{array}{l}\text { Standard } \\
\text { Deviation }\end{array}$ & Variance & Mode & Median \\
\hline Scaled Ques. & 2.75 & 1.20 & 1.43 & 3 & 3 \\
28-35 & 2.65 & 1.21 & 1.47 & 2 & 3 \\
Domestic & 3.00 & 1.12 & 1.26 & 3 & 3 \\
International & & & & & \\
\hline
\end{tabular}

\section{Table 8}

ANOVA Outcomes

\begin{tabular}{lccc}
\hline Scale & ANOVA p-value & Effect Size & Stat Sig \\
\hline Ques. 1-12 & 0.0100 & 0.005 & Yes \\
Ques. 13-27 & 0.0503 & 0.001 & None \\
Ques. 28-35 & 0.0000 & 0.002 & Yes \\
\hline
\end{tabular}

Note. The significance level was 0.05 .

Statistically significant outcomes were observed for the first and the third scales. No statistically significant difference was detected for the second scale. Respectively, the first and the third scales examined whether plagiarism was perceived as a necessary evil and whether plagiarism was illegal. The analysis of the means in the first scale showed that both groups tended toward disagreement with respect to the notion that plagiarism is a necessary evil. Within the first scale, the domestic group mean was 1.93, whereas the international group mean was 2.09. With respect to the third scale, the 
analysis of the means showed that both groups tended toward neutrality regarding the notion that plagiarism is illegal. Within the third sale, the domestic group mean was 2.65, whereas the international group mean was 3.00.

\section{CONCLUSIONS AND RECOMMENDATIONS}

Although the outcomes of this study may not be generalizable to any larger arrays of students nationally, the host institution gained insight into the mindsets of its students. The host institution was primarily a teaching institution located within a rural setting. A total of 312 students were enrolled in the College of Business. Class sizes were small, and exhibited a ratio of 1 faculty per 15 students. Degree programs in the College of Business consisted of accounting, finance, management, marketing, information systems, and technology. Similar institutions may find the outcomes of this study useful when crafting policies and activities toward abating plagiarism.

Regarding scaled items 1 through 12 , it is concluded that a statistically significant difference exists regarding the perceptions between the domestic and international student groups with respect to the notion that "plagiarism is a necessary evil." It is revealed that both groups disagreed with this notion. Thus, it is concluded that plagiarism is not perceived as a necessary evil among both groups of respondents.

It is concluded that scaled items 13 through 27 showed no statistically significant difference. This scale represented the notion that "plagiarism is unprofessional." Given the mean analysis of this scale, respondents expressed neutrality (i.e., neither agreeing nor disagreeing) regarding this issue. Therefore, few, if any, characteristics of unprofessionalism are discerned among both groups of respondents.

Data for items 28 through 35, revealed that a statistically significant difference exists with respect to the notion that "plagiarism is illegal" between domestic and international students. Given the mean analysis of this scale, respondents expressed neutrality (i.e., neither agreeing nor disagreeing) regarding this issue. Few, if any, characteristics of illegality are discerned among the respondents. 
Because both students and faculty are aware of the organizational policies regarding plagiarism throughout the duration of any course, no excuse exists for plagiaristic activities. Ample and gracious opportunities exist wherein students have sufficient resources that contribute toward the timeliness of fashioning original concepts and compositions, both professionally and academically. Given these notions, such awareness among both students and faculty contributes toward the averting of plagiarist activities.

The bulk of the respondents were undergraduates that have never experienced professional work settings. Therefore, youth and inexperience may contribute toward a lack of full understanding of professionalism in its experiential, practical, and ideological forms. Only time and experience will better their understanding of professionalism whereby they may possess a greater capacity for judging the notion that "plagiarism is unprofessional."

Pondering the neutrality of the responses to this question generates an additional question: perhaps the respondents are ignorant of copyright law, and do not feel capable of accurately responding? Although plagiarism may be perceived ethically as a form of intellectual theft, perhaps the respondents do not believe it to be a truly criminal action given that students are neither jailed nor sued for plagiarist actions among academic settings? The respondents consisted of international students from a variety of different nations, especially China. It is possible that some cultural influences may have impacted the responses to this question. For instance, among the international group, some students simply may not have understood the question itself because their cultures not only permit and encourage the exact repetition of the thoughts, works, and ideologies of others, but expect them to occur societally.

Within the context of the overall research question involving the notion whether plagiarism is unethical and a stain within the scientific community, it is concluded that both groups tended toward disagreement with the notion that plagiarism is a necessary evil. In other words, both groups did not believe that plagiarism was something that must be done in order to complete an assignment.

The means analyses showed similarities in the attitudes of domestic and international students. Such similarity contrasts with the preceding descriptions of international students receiving much 
attention from instances of plagiarism. The similarity is interesting when realizing that American culture differs from the national cultures expressed by the respondents. One must consider the survey responses with a grain of salt. For instance, at the University of Minnesota, Mundava \& Chaudhuri (2007) showed that approximately $85 \%$ of plagiarism instances were associated with students whose native tongues were not English, and Bretag (2013, p. 1) indicated that that international students were at least "twice as likely as domestic students" to misunderstand various methods of avoiding academic breaches of integrity. Within this study, some of the respondents originated from Asian culture in which using the words, ideas, and concepts of another is viewed as a method of revering or praising the individual and may be an expected aspect of culture and society. Given this notion, a question is mindful: perhaps some respondents answered questions in a way in which they hoped to be perceived by the university, and not truthfully? In other words, perhaps some respondents answered questions in a fashion that would satisfy the expectations of the institution, but did not provide their truthful opinions?

Another consideration of mean analysis similarity involves differences of laws among nations with respect to the aforementioned cultural differences. Within the U.S., plagiarism is not illegal, but is considered unethical and immoral. Overseas, some cultures may expect and advocate the exact use of another's words, concepts, and ideas without legal retribution. In both cases, no punitive actions exist legally to punish offenders. Even if a student interpreted the question from the perspective of U.S. laws or the laws of their home country, it could be possible that respondents answered truthfully regarding this issue because no type of plagiarism law exists to sanction and punish plagiarists. The host institution may consider emphasize greater consideration of copyright and plagiarism within its ethics and business law classes to show how such concepts affect collegiate settings.

The mean analysis revealed that similarity of opinions existed regarding the unprofessionalism query. Both groups exhibited neutrality regarding this issue. Both the domestic and international students represented young people who possessed little experience professionally. Although their future occupations may be classified 
as professions, they have not entered professional employment yet and lack an understanding of expectations among professional work settings. Therefore, inexperience and unfamiliarity may underlie the common findings of neutrality. The host institution may provide some introduction to professionalism within its professional development courses during the junior and senior years. During this period, the host institution may emphasize that plagiarism and copyright violations are disallowed among professional settings.

The host institution entered into its international agreements five years ago. Before these agreements existed, it exhibited few international students, and considered the closure of degree programs in business because of low enrollment quantities. Prior to its international agreements, the College of Business had little experience with international students or instances of plagiarism involving international students. Greater quantities of international students spared these programs from closing. However, as enrollments increased, more instances of plagiarism occurred that necessitated the forming of additional committees to address instances of alleged academic misconduct. In various cases, students admitted to plagiarism. In other cases, it was determined that plagiarism was unintentional, and was attributed to language unfamiliarity or an incomplete understanding of plagiarism. Some international students indicated that their opinion or thoughts about a topic were the exact same as someone else's, and believed that they could copy and use verbatim the words and materials of a classmate who had already completed an assignment as their own work.

In the hope of abating plagiarism, the host institution used the outcomes of this study to craft workshops for incoming international students to better clarify expectations of writing and speaking in the academic environment. Professional seminar courses were also developed and mandated for the junior and senior years. These courses further clarified the expectations of writing and speaking among professional work settings, and emphasized that plagiarism was unallowable in work settings. The institution developed a writing assessment upon initial entry into the academic setting to identify students whose writing samples exhibited plagiarism. Given the outcomes of this study, the College of Business may also craft new policy and better define existing policy regarding plagiarism. Law and 
policy are not identical. Although no law exists to punish collegiate acts of plagiarism, university policy may be better defined to specify punitive sanctions and punishments. University policy may be crafted toward a series of interventions that contribute toward combating plagiarism while improving the speaking and writing skills of both domestic and international students. As a result, students may be counseled early within their studies to avert future instances of plagiarism that would necessitate expulsion. Such counseling may improve student retention and success rates through time.

The host institution may consider this study from the perspectives of organizational competitiveness and attractiveness within the academic market. Competitiveness within the academic market is enhanced by institutional reputation, perceptions of academic program strength, and satisfying niche market needs (Davies \& Hammack, 2005; Doss, et al., 2015c).

Various recommendations may be contemplated. It is recommended that the host institution reexamine the data set using different stratifications among the respondents. The demographics also showed a variety of international origins representing China, Europe, Mexico, and the Pacific Islands. Future studies may explore the same research question and hypotheses within and between these groups.

Certainly, the host institution may invoke any number of combinations of demographic attributes whereby future studies may be performed. Examples include examining day versus night students, part-time versus full-time students, and so forth. Regardless, such investigations are constrained solely to the host institution. Further, the host institution may consider performing the study again via a comparison between its Division II domestic and international students and the students from a neighboring Division I research institution. Given this notion, it is recommended that the host institution approach other institutions and cooperate to determine whether any differences of perceptions exist between separate student groups. 


\section{REFERENCES}

Bista, K. (2011). Academic dishonesty among international students in higher education. In J. Miller \& J. Groccia (Eds.), To improve the academy: Vol. 30. Resources for faculty, instructional, and organizational development (pp. 159-172). San Francisco, CA: Jossey-Bass.

Bretag, T. (2013). Challenges in addressing plagiarism in education. PLoS Medicine, 10, e1001574. doi:10.1371/journal.pmed.1001574

Cowling, M.G. (2012). The future of mathematical publishing. Notices of the AMS, 59, 558-559. doi:http://dx.doi.org/10.1090/noti820

Currie, P. (1998). Staying out of trouble: Apparent plagiarism and academic survival, Journal of Second Language Writing, 7, 118. doi:10.1016/S1060-3743(98)90003-0

Davies, S. \& Hammack, F.M. (2005). The channeling of student competition in higher education: Comparing Canada and the U.S. The Journal of Higher Education, 76(1), 89-106.

Demers, J.T. (2006). Steal this music: How intellectual property law affects musical creativity. Athens, GA: University of Georgia Press.

Doss, D.A., Allen, A., Henley, R., McElreath, D., Miller, L., \& Hong, Q. (2015a, May). An analysis of graduate vs. undergraduate opinions of business students regarding plagiarism. Paper presented at the meeting of the Academic Business World International Conference \& International Conference on Learning and Administration in Higher Education. Nashville, TN.

Doss, D.A, Glover, W.H., Goza, R.A., \& Wigginton, M. (2015b). The foundations of communication in criminal justice systems. Boca Raton, FL: CRC Press.

Doss, D., Jones, D., Sumrall, W., Henley, R., McElreath, D., Lackey, H., Gokaraju, B. (2015c). A net present worth analysis of considered academic programs at a private, regional higher education institution. Journal of Interdisciplinary Studies in Education, 4(1), 55-77. 
Dyer, O. (2011). Alberta university medical dean resigns after students detect plagiarism in his speech. The BMJ. 342, doi: http://dx.doi.org/10.1136/bmj.d4038

Howard, S., Ehrich, J., \& Walton, R. (2014). Measuring students' perceptions of plagiarism: Modification and Rasch validation of a plagiarism attitude scale. Journal of Applied Measurement, 15(4), 372-393.

Lose, G. (2011). Plagiarism, International Urogynecology Journal, 22, 903-904. doi: 10.1007/s00192-011-1437-9

Maurer, H., Kappe, F., \& Zaka, B. (2006). Plagiarism - a survey. Journal of Universal Computer Science, 12, 1050-1084.

McElreath, D.H., Doss, D.A., Jensen, C.J., Wigginton, M., Kennedy, R., Winter, K.R., Mongue, R.E., Bounds, J., \& Estis-Sumerel, J.M. (2013). Introduction to law enforcement. Boca Raton, FL: CRC Press.

McNabb, D.E. (2010). Research methods for political science: Quantitative and qualitative approaches ( ${ }^{\text {nd }}$ ed.). Armonk, NY: M.E. Sharpe Publishing.

Mundava, M. \& Chaudhuri, J. (2007). Understanding plagiarism: The role of librarians at the university of Tennessee in assisting students to practice fair use of information, College and Research Libraries News, 68, 1-5.

Posner, R.A. (2007). The little book of plagiarism. New York, NY: Pantheon Books.

Qi, L. (2015). U.S. schools expelled 8,000 Chinese students. Retrieved from http://blogs.wsj.com/chinarealtime/2015/05/29/u-s-schoolsexpelled-8000-chinese-students-for-poor-grades-cheating/

Shah, A. (2012). Plagiarism: The bete noire of scientific communication. Indian Journal of Chest Disease and Allied Science, 54, 87-89.

Tappen, R.M. (2011). Advanced nursing research: From theory to practice. Sudbury, MA: Jones and Bartlett Publishing.

Towell, E., McFadden, K.L, McCoy, W.C., \& Buhrow, A. (2012). Creating an interdisciplinary business ethics program. Journal of Academic Ethics, 10, 93-112. doi:10.1007/s10805-0129160-9 
University of West Alabama. (2015). Bulletin of the school of graduate studies. Livingston, AL: University of West Alabama.

University of West Alabama. (2016). Transfer international students.

Retrieved from: http://www.uwa.edu/uploadedFiles/Admissions_and_Aid/Inter national_Students/Transfer_International.pdf

Wilkinson, J. (2009). Staff and student perceptions of plagiarism and cheating. International Journal of Teaching and Learning in Higher Education, 20, 98-105.

Yang, Y (2014). Why students plagiarize in organic chemistry laboratory course?--A case at Heibei University of Technology in China. 2014 IEEE Symposium on Ethics in Science, 1-4. doi: 10.1109/ETHICS.2014.6893443

Zhang, D., Joy, M., Cosma, G., Boyatt, R., Sinclair, J., \& Yau, J. (2013). Source-code plagiarism in universities: A comparative study of student perspectives in China and the UK. Assessment \& Evaluation in Higher Education, 39, 743-758. doi:10.1080/02602938.2013.870122

DANIEL DOSS, PhD, is an associate professor of computer information systems and director of the MBA program at the University of West Alabama. His research interests are information systems, homeland security, and criminal justice. Email: adoss@uwa.edu

RUSS HENLEY, $\mathrm{PhD}$, is an associate professor of marketing at the University of West Alabama. His research interests are marketing, advertising, consumer behavior, and behavioral marketing. Email: rhenley@uwa.edu

BALAKRISHNA GOKARAJU, PhD, is an assistant professor of engineering technology at the University of West Alabama. His research areas are technology, engineering, and higher education. Email: bgokaraju@uwa.edu

DAVID MCELREATH, $\mathrm{PhD}$, is a professor of legal studies at the University of Mississippi. His research areas are criminal justice, law 
enforcement, corrections, and homeland security. Email: dhmcel@olemiss.edu

HILLIARD LACKEY, PhD, is an associate professor of urban higher education at Jackson State University. His research areas are higher education, history, and geography. Email: hilliard.lackey@jsums.edu

QIUQI HONG, BBA, is an MBA graduate student at the University of West Alabama. Her research area is general business administration. Email: hongq@uwa.edu

LAUREN MILLER, BBA, is an MBA graduate student at the University of West Alabama. Her research areas are general business administration and finance. Email: miller119643@uwa.edu

Manuscript submitted: November 5, 2015 Manuscript Revised: January 4, 2016 Accepted for publication: March 5, 2016 